\title{
Development of the germinal ridge and ovary in the African elephant (Loxodonta africana)
}

\author{
F J Stansfield ${ }^{1,2}$, J O Nöthling ${ }^{2}$, J T Soley ${ }^{3}$ and W R Allen ${ }^{1,4}$ \\ ${ }^{1}$ The Elephant Research and Conservation Unit, Savé Valley Conservancy, Chiredzi, Zimbabwe, Departments of \\ ${ }^{2}$ Production Animal Studies and ${ }^{3}$ Anatomy and Physiology, Faculty of Veterinary Science, University of Pretoria, \\ Onderstepoort 0110, Republic of South Africa and ${ }^{4}$ The Paul Mellon Laboratory, 'Brunswick', 18 Woodditton Road, \\ Newmarket, Suffolk CB89BJ, UK
}

Correspondence should be addressed to FJ Stansfield at The Elephant Research and Conservation Unit, Savé Valley Conservancy, Chiredzi; Email: fjs@yoafrica.com

\begin{abstract}
The follicular reserve and its ontogeny in the elephant are of interest because elephants have the longest reproductive life of all landbased mammals. They also have the longest recorded pregnancy, which allows a protracted view of the series of significant events involved in the development of the embryonic and fetal gonads. The large elephant population of Zimbabwe provided the opportunity to collect conceptuses from elephants culled for management reasons and hunted professionally. Five embryos aged 76-96 days and the ovaries of four fetuses aged 4.8-11.2 months were fixed in 4\% buffered formalin and studied by conventional histological sectioning and a stereological protocol to calculate the follicle reserve of each fetus. These observations enabled the conclusion that the migration of primordial germ cells into the indifferent gonad terminates at around 76 days of gestation while entry of oogonia into meiosis along with first follicle formation starts at around 5 months. Peak numbers of follicles are present by mid-gestation towards the end of the 6-month mitotic-meiotic transition period. It appears that the cortex of the elephant fetal ovary at mid-gestation (11 months) has already reached a developmental stage exhibited by the ovaries of many other mammals at full term.

Reproduction (2012) 144 583-593
\end{abstract}

\section{Introduction}

The elephant has the longest gestation period (656 days) of all land-based mammals (Moss \& Poole 1983, Meyer et al. 2004) and it demonstrates a remarkably flat fetal growth curve during the first half of this period (Craig 1984). Two previous studies have examined embryonic development in the elephant. The first highlighted the aquatic ancestry of elephantids as evidenced by the development of the trunk, the internal placement of the testes in the male, the unusual structure of the pleural cavity in post-natal life and the presence of fish-like nephrostomes in the embryonic and fetal kidney (Gaeth et al. 1999). The second mapped embryonic and early fetal development during the first 200 days of gestation by comparing trans-rectal ultrasound scans of the conceptus in zoo elephant with known mating dates to 22 elephant fetuses recovered during culling operations in South Africa (Hildebrandt et al. 2007). Using this information, a formula was produced, which may be used to age embryos and fetuses from the time they are first measurable ultrasonically at 50 days through to 202 days of gestation. This improves on the previous formula utilising fetal weight that was devised by Craig (1984).
Existing dogma holds that the complement of oocytes for adult reproductive life is established during fetal life or, in a small number of species, during early neonatal life (Gosden 2004). There has, however, been considerable speculation over the past decade as to whether postnatal neo-oogenesis can occur to replenish oocyte stocks in pre-pubertal and adult life (see de Felici (2010), and Gougeon \& Notarianni (2011) for reviews). The process of formation of the ovarian reserve is similar throughout the mammalian kingdom, although time scales and gestation lengths vary greatly. Oogenesis begins with the migration of primordial germ cells (PGCs) from their extra-embryonic origin in the yolk sac to the indifferent gonadal ridge, which develops as an outgrowth from the mesonephros (McLaren 2003). Having divided mitotically during their journey, the PGCs arrive at the gonadal ridge where they loose their pluripotency and are now termed oogonia (Byskov \& Nielsen 2010) or simply germ cells if the sex of the embryo is not obvious. Mitotic multiplication continues within the gonadal ridge and is key to the establishment of the future oocyte population as it is the balance between mitotic production and apoptotic elimination of oogonia, which determines the number of oocytes available for reproductive life in 
the female mammal (Aitken et al. 2011). The signal for oogonia to stop mitotic division and start meiotic differentiation is unclear, but it is thought to be associated with the presence of retinoic acid originating from the mesonephros (Bowles \& Koopman 2007, Childs et al. 2011). Entry into meiotic prophase marks the end of germ cell production in the mammalian ovary according to generally accepted dogma (Gougeon \& Notarianni 2011). This involves the progression of the oogonia through the first four stages of prophase to the diplotene stage where DNA duplication having taken place the germ cell, now termed an oocyte, arrests development. The oocytes then remain meiotically dormant until just before ovulation in the select few oocytes, which are destined to progress towards fertilisation. The length of a single meiotic prophase to the time of arrest is estimated to be approximately a week in the mouse, rat and hamster and 12-15 days in the rabbit, dog, pig monkey and man (Deanesly 1977). However, the duration of the period in which oogonia enter meiosis is long and is suggested to be related to gestation length, e.g. 52-82 days in the ewe, 40-100 days in the sow, 70-170 days in the cow, 70-140 days in the macaque and 82-160 days in women (Deanesly 1977). In the hamster, rabbit, ferret and dog, entry into meiosis occurs post-natally (Deanesly 1977). In most species, these newly formed follicles are termed primordial follicles with each oocyte being surrounded by a layer of flattened granulosa cells (Pepling 2012). Oocytes that are not captured within follicles continue through meiosis and become atretic (Anderson et al. 2000).

In the elephant, the granulosa cells surrounding the earliest follicles are not flattened, some are cuboidal in shape and such follicles are therefore termed early primary (Oktay 1995). Such follicular development has also been noted in bovine ovaries (Van Wezel \& Rodgers 1996). As described previously by Stansfield et al. $(2011 b)$, the small follicle (SF) pool or reserve in the elephant is composed of early primary (an oocyte surrounded by a single layer of granulosa cells that may be flat or cuboidal in shape) and true primary follicles (an oocyte surrounded by a single layer of granulosa cells all of which are cuboidal in shape), which together have been termed SFs; there are almost no primordial follicles (oocytes surrounded by a single layer of flattened granulosa cells) in the ovaries of elephants of all ages. During oogenesis in all species, peak numbers of germ cells are observed around the time of the transition from mitosis to meiosis (Reynaud \& Driancourt 2000). From their peak at embryonic day 13 in the mouse (E13), E80 in cattle and E152 in woman, the number of germ cells decreases sharply, with two main periods of high loss: i) the pachytene (recombination) stage of meiosis in the oocyte and ii) the time of formation of primordial follicles (Reynaud \& Driancourt 2000, Bendsen et al. 2006, Aitken et al. 2011). As a consequence of these considerable losses, the number of oocytes enclosed in primordial follicles at birth in the cow, for example, is $<5 \%$ of the peak value (Reynaud \& Driancourt 2000). The highest survival rate of germ cells in domestic mammals occurs in the pig where approximately half the original number of germ cells persist until birth (McGeady et al. 2006).

This study was undertaken to monitor the development of the elephant ovary, from its early indifferent stage before 100 days of gestation until it begins to enlarge greatly in mid-pregnancy due to hypertrophy and hyperplasia of interstitial cells in the medulla and the development of multiple antral follicles. It follows a previous study that examined the morphology, oogenic
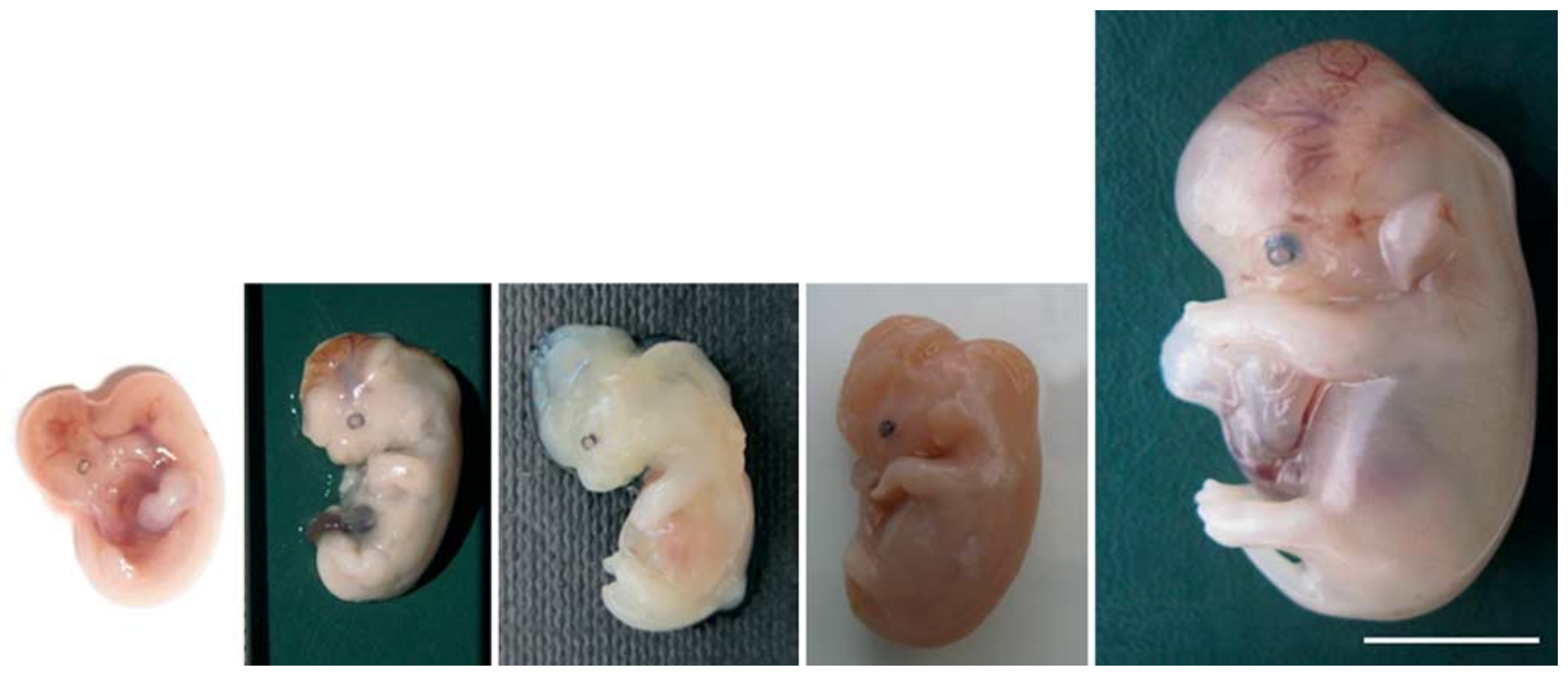

Figure 1 African elephant embryos aged (from left to right) 76, 81, 82, 87 and 96 days post-conception. Scale bar=10 mm. 
Table 1 Mass, crown-rump length (CRL) and estimated ages of the five elephant embryos.

\begin{tabular}{lccccc}
\hline & & \multicolumn{3}{c}{ Estimated age (days) } \\
\cline { 3 - 6 } Embryo & Mass (g) & CRL (mm) & $\begin{array}{c}\text { Based } \\
\text { on mass }\end{array}$ & $\begin{array}{c}\text { Based } \\
\text { on CRL }\end{array}$ & $\begin{array}{c}\text { Used in } \\
\text { the study }\end{array}$ \\
\hline 1 & 0.47 & 14 & 76 & 76 & 76 \\
2 & 0.50 & 16 & 77 & 78 & 81 \\
3 & 0.55 & 23 & 78 & 87 & 82 \\
4 & 0.75 & 25 & 80 & 89 & 87 \\
5 & 3.00 & 34 & 94 & 98 & 96 \\
\hline
\end{tabular}

${ }^{a}$ Age according to body mass as formulated by Hildebrandt et al. (2007).

${ }^{\mathrm{b}}$ Age according to CRL as formulated by Hildebrandt et al. (2007).

and steroidogenic functions of the elephant ovary during late fetal and post-natal and pre-pubertal life (Stansfield et al. 2012).

\section{Results}

\section{Milestones in embryonic development}

The earliest specimen studied at 76 days of gestation (2.5 months; Fig. 1 and Table 1) exhibited a 'cauliflower floret'-shaped gonadal ridge on the ventral surface of the relatively large mesonephros on each side of the abdomen (Fig. 2a). Coelomic epithelium formed a dense outer lining of the presumptive gonad (Fig. 2a and b) and it penetrated inwards as cortical cords between the mesothelial stromal cells. Germ cells with an overall diameter of $12.5 \mu \mathrm{m}$ and a nuclear diameter of $\sim 10.0 \mu \mathrm{m}$ were observed within the stroma of the still indifferent gonad (Fig. 2b), which demonstrated a two-dimensional profile in the sagittal plane of $\sim 1200 \times 350 \mu \mathrm{m}$. Immediately medial to each gonadal ridge, both cranially and caudally, PGCs of indeterminate status were also visible, some of which were binucleate (Fig. 2c).

Sagittal sections of embryo 2 (Fig. 1) were cut, but these were not suitable for morphological study due to delayed fixation and poor staining. The embryo was, however, useful for ageing criteria using external morphology and measurements (see Table 1).

At 82 days of gestation (2.7 months; embryo 3), development of the gonad was well advanced, although it was still attached in two places to the mesonephros. It demonstrated a two-dimensional profile of $\sim 1140 \times$ $750 \mu \mathrm{m}$ in the sagittal plane and it still lacked visible
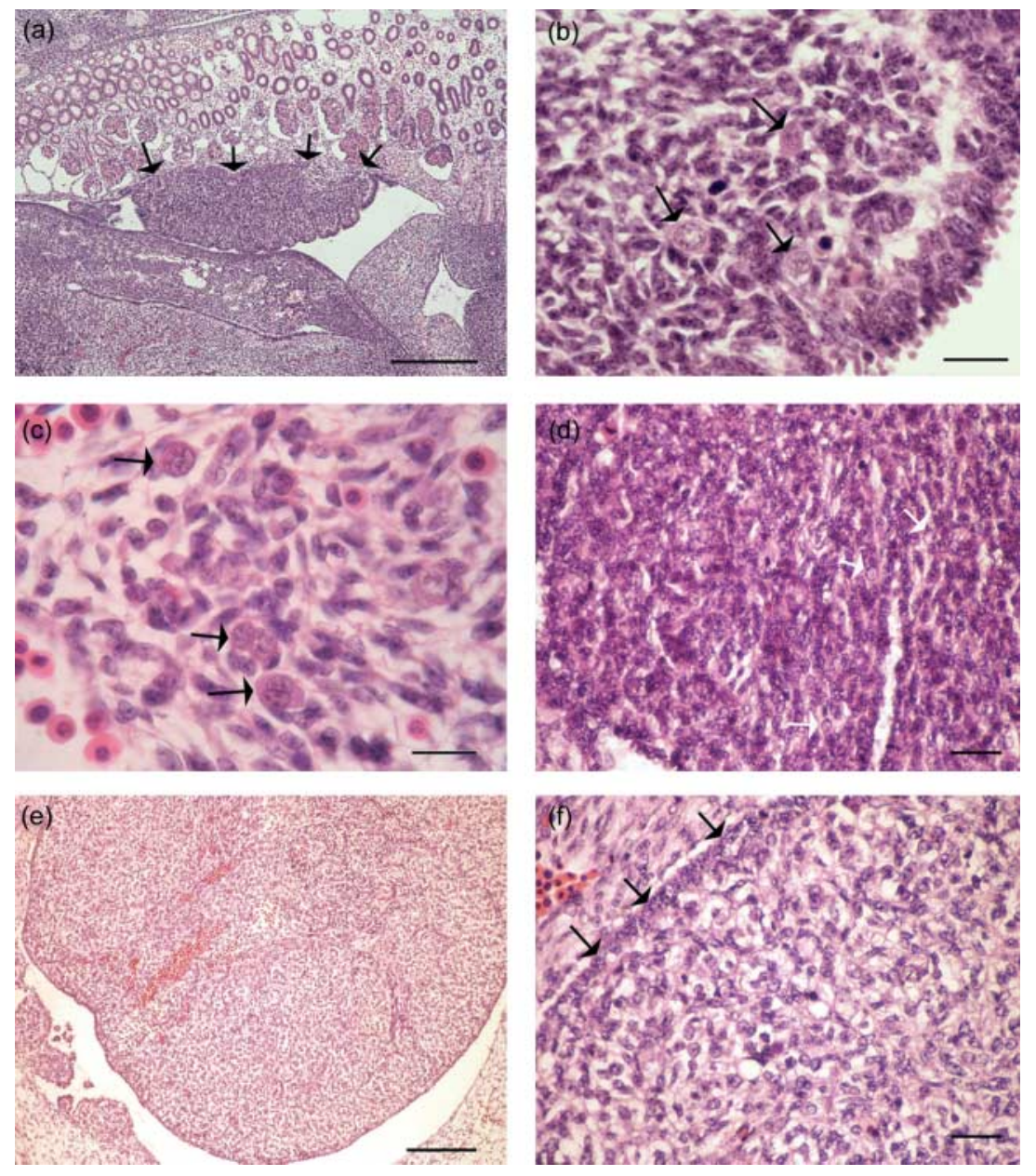

Figure 2 Photomicrographs of the indifferent gonads of African elephant embryos. (a) The gonadal ridge of a 76-day-old embryo; black arrows mark the boundary of the gonad and mesonephros. Scale bar $=350 \mu \mathrm{m}$. (b) Germ cells (black arrows) within the gonadal ridge in the 76-day embryo. Note the thick coelomic epithelium lining the presumptive gonad. Scale bar $=20 \mu \mathrm{m}$. (c) Migrating germ cells (black arrows) observed in the tissues dorsal and medial to the gonadal ridge in the 76-day embryo. Scale bar $=20 \mu \mathrm{m}$. (d) At 82 days post-conception, the germ cells (white arrows) are smaller and therefore difficult to identify between the blastema. Scale bar $=40 \mu \mathrm{m}$. (e) By 96 days post-conception, the gonad is a roughly spherical, independent organ. Scale bar $=125 \mu \mathrm{m}$. (f) Higher magnification of part of the gonad illustrated in (e). Germ cells are difficult to distinguish from the other cells within the blastemal mass of the stroma. Black arrows mark the cuboidal epithelial cells at the surface of the gonad. Scale bar $=40 \mu \mathrm{m}$. 
Table 2 Germ cell size in the elephant embryonic and fetal gonad and the number of granulosa cells surrounding the oocyte for different types of small follicles.

\begin{tabular}{|c|c|c|c|c|c|c|}
\hline \multirow{2}{*}{$\begin{array}{l}\text { Embryo or } \\
\text { fetus number }\end{array}$} & \multirow{2}{*}{$\begin{array}{l}\text { Age months } \\
\text { (days) }\end{array}$} & \multirow{2}{*}{$\begin{array}{l}\text { Type of cells } \\
\text { or follicles }\end{array}$} & \multicolumn{3}{|c|}{ Diameter $(\mu \mathrm{m})$} & \multirow{2}{*}{$\begin{array}{l}\text { No. of } \\
\text { granulosa cells }\end{array}$} \\
\hline & & & Follicle & Oocyte & Nucleus & \\
\hline Embryo 1 & $2.5(76)$ & Germ cells ${ }^{\mathrm{a}}$ & - & 12.5 & 10.0 & - \\
\hline Embryo 2 & $2.7(81)$ & ND & - & ND & ND & - \\
\hline Embryo 3 & $2.7(82)$ & Germ cells & & 15.0-16.0 & 10.0-10.5 & - \\
\hline Embryo 4 & $2.9(87)$ & ND & - & ND & ND & - \\
\hline Embryo 5 & $3.2(96)$ & ND & - & ND & ND & - \\
\hline Fetus 1 & 4.8 & Oogonia & - & 15.0-20.0 & $7.8-10.0$ & - \\
\hline Fetus 2 & 5.3 & Oogonia & - & $16.0-25.0$ & $10.0-12.5$ & - \\
\hline \multirow[t]{2}{*}{ Fetus 3} & 5.9 & Oogonia & - & $17.5-25.0$ & $10.0-12.5$ & - \\
\hline & & SF & $35.0-37.5$ & $21.5-23.0$ & $14.0-16.5$ & $8-11$ \\
\hline \multirow[t]{2}{*}{ Fetus 4} & 11.2 & $\mathrm{EP}$ & $47.5-65.0$ & $45.0-55.0$ & $20.0-22.5$ & $12-14$ \\
\hline & & TP & $55.0-105$ & $60.0-80.0$ & $20.0-22.5$ & $21-30$ \\
\hline
\end{tabular}

ND, no data; PGC, primordial germ cells; SF, small follicles; EP, early primary follicles; TP, true primary follicles.

${ }^{a}$ Germ cells not yet identifiable as oogonia or pre-spermatogonia because gonadal sex differentiation has not yet occurred.

internal organisation. Some large germ cells, with nuclear diameters similar to those present in embryo 1 at 2.5 months (Table 2), were observed while germ cells of smaller $(7.5 \mu \mathrm{m})$ nuclear diameter were also visible. These smaller cells, which were possibly mitotic, were difficult to distinguish from the invading coelomic epithelial cells (Fig. 2d).

At 87 days (2.9 months; embryo 4), the gonad displayed a two-dimensional profile of $\sim 1240 \times$ $670 \mu \mathrm{m}$ in the sagittal plane and was attached to the mesonephros only by a thin stalk, presumably the precursor of the mesovarium. The surface epithelium comprised a layer of cuboidal epithelial cells with some interspersed germ cells. The germ cells were distributed throughout both gonads, although they were less obvious than during earlier developmental stages. No PGCs were observed in tissues outside the gonads.

At 96 days (3.2 months; embryo 5), the gonads were now relatively large, rounded structures with a twodimensional profile of $\sim 1500 \times 1175 \mu \mathrm{m}$ in the sagittal plane. Each gonad displayed a single point of attachment to the mesonephros. Very few germ cells could be distinguished from the pre-granulosa and other cells within the blastemal mass of the stroma (Fig. 2e and f), but blood vessels were visible penetrating the organ from the point of attachment to the mesonephros. The epithelial lining was similar to that seen in the previous developmental stage (Fig. 2f). Sexual differentiation of the gonad was still not apparent.

\section{Milestones in fetal development}

Using the two established ageing formulae, fetus 1 (Fig. 3a) was calculated to be between 4.8 months (Hildebrandt et al. 2007) and 6.2 months (Craig 1984) of age. Phenotypically, it was clearly female and the two ovaries had volumes of 39 and $46 \mathrm{~mm}^{3}$ respectively (Table 3 and Fig. 3b). Their surface epithelium (ovarian surface epithelium, OSE) consisted primarily of low cuboidal mesothelial cells, which were multilayered in places. These surface epithelial cells were rarely observed to extend into the developing gonad and the OSE was separated in the most part from underlying pockets of round cells by a layer of fusiform mesenchymal cells. The pockets of large round cells were present throughout the ovary (Fig. 3c). They were isolated from the surrounding stroma by tracts of fibroblast-like cells with elongated nuclei. No basement membrane was visible beneath the epithelial layer. The round cells were of two sizes. The larger, more plentiful ones (cell diameter range $15-20 \mu \mathrm{m}$ ) were the oogonia still attached by cell bridges in germline cysts or nests (Pepling 2006), and the smaller ones (cell diameter range 8-12 $\mu \mathrm{m}$ ) were possibly the pre-granulosa cells that, although in close proximity to the oogonia, were not yet adherant to them in any sort of follicle formation. The nuclei of the oogonia were typically $7.8-10 \mu \mathrm{m}$ in diameter (Table 2), although some were as large as $15 \mu \mathrm{m}$. By contrast, the smaller pre-granulosa cells had nuclear diameters of only around $5 \mu \mathrm{m}$. The nests of oogonia occurred throughout the ovary with the exception of the immediate area of attachment hilum of the suspensory ligament, which was composed of loosely packed stromal cells and some blood vessels. Stromal cells were more densely arranged in the centre of the ovary where they created the impression of spreading out from the point of ovarian attachment to surround the nests of oogonia. The peripheral aspect of the ovary displayed fewer stromal cells between the oogonial nests.

Fetus 2 was aged between 5.3 months (Hildebrandt et al. 2007) and 6.6 months (Craig 1984). The mean volume of its two ovaries was $50 \mathrm{~mm}^{3}$. The OSE consisted of three to four layers of very densely packed cells, which protruded as wavy cell cords into the presumptive cortex. Oogonia were separated from the OSE and each other by more numerous ingressed epithelial cells and approximately two-thirds of them fell within the developing cortical region. From the hilum, fibroblasts branched out in tree-like fashion 

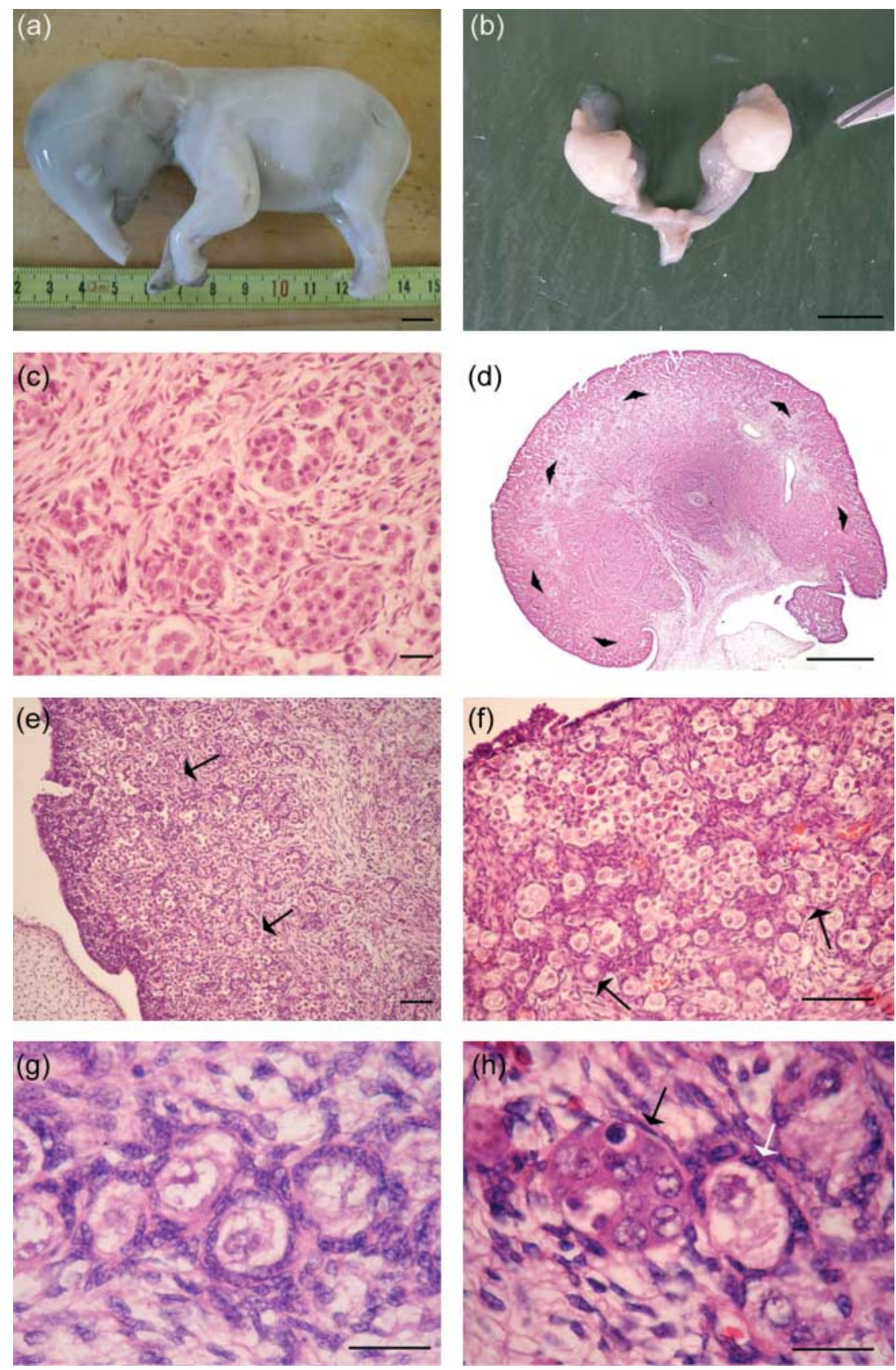

Figure 3 Photographs and photomicrographs of the gonads of elephant fetuses aged 4.8-5.9 months of gestation. (a) A 4.8-month-old fetus (the lower half of the trunk is missing). Scale bar $=10 \mathrm{~mm}$. (b) The ovaries and uterus of the 4.8-month fetus. Scale bar $=3 \mathrm{~mm}$. (c) Pockets of oogonia surrounded by fibroblasts present throughout the ovaries of the 4.8-month fetus. Scale bar $=30 \mu \mathrm{m}$. (d) Cross section through the ovary of the 5.3-month fetus. The inner limits of the developing cortical region are marked by black arrow heads. Scale bar $=1 \mathrm{~mm}$. (e) Higher magnification of the ovary in (d) showing oocytes in the cortical region, both on the presumptive cortico-medullary border (black arrows) and within the medulla. Scale bar $=100 \mu \mathrm{m}$. (f) Oogonia within the ovigerous cords of a 5.9-month-old fetal ovary. The cords reach from just below the surface epithelium to the presumptive cortico-medullary border (black arrows). Scale bar $=100 \mu \mathrm{m}$. (g) Newly formed follicles in the same ovary as (f). The string of follicles extends from the end of ovigerous cords from which the follicles finally 'bud-off'. Note the number and shape of the pre-granulosa cells. Scale bar $=30 \mu \mathrm{m}$. (h) A small follicle (white arrow) in the medulla, alongside an ovigerous cord containing oogonia (black arrow). Scale bar $=30 \mu \mathrm{m}$.
(Fig. 3d) in 'cell streams' as described by Zamboni et al. (1979) to invade all parts of the ovary and right up to the OSE in places. In the $25 \mu \mathrm{m}$ sections, these cell streams were commonly observed to be associated with darker staining endothelial cells forming blood vessels. In circumscribed areas, the elongated fibroblasts were positioned parallel to the surface of the ovary in the region consistent with the final placement of the future cortico-medullary border. A few SFs were sparsely dispersed throughout the central region of the ovary and along the presumptive cortico-medullary border where they occurred individually or in strings (Fig. 3e). Many nests of oogonia remained intact in the vicinity of the mesovarium and in the medulla, although the centrally placed oogonia were less densely arranged than in fetus 1 .

At 5.9 (Hildebrandt et al. 2007) to 7.2 months (Craig 1984), the mean ovarian volume was $82.5 \mathrm{~mm}^{3}$. The OSE of fetus 3 composed of a predominantly single layer of very densely packed cells and no basement membrane was visible. Situated just beneath this layer (Fig. 3f) were ovigerous cords containing oogonia and some pre-granulosa cells. The region displaying these cords extended for approximately two-thirds of the depth of the presumptive cortex which now, typically, measured 500-875 $\mu \mathrm{m}$ in width. Deeper within the 
Table 3 Ovarian volumes $\left(\mathrm{mm}^{3}\right)$ of elephant fetuses.

\begin{tabular}{lccccc}
\hline Fetus & $\begin{array}{c}\text { Age } \\
\text { (months) }\end{array}$ & Ovary $^{\text {a }}$ & Cortex & Medulla & $\begin{array}{c}\text { Whole } \\
\text { ovary }\end{array}$ \\
\hline 1 & 4.8 & $\mathrm{~L}$ & - & - & 39 \\
& & $\mathrm{R}$ & - & - & 46 \\
2 & 5.3 & $\mathrm{~L}$ & 17.7 & 26.7 & 44 \\
& & $\mathrm{R}$ & 19.2 & 35.7 & 55 \\
3 & 5.9 & $\mathrm{~L}$ & 35.0 & 50.0 & 85 \\
& & $\mathrm{R}$ & 33.5 & 46.9 & 80 \\
4 & \multirow{2}{*}{11.2} & $\mathrm{~L}$ & 925 & 1719 & 2644 \\
& & $\mathrm{R}$ & 622 & 1684 & 2306 \\
\hline
\end{tabular}

cortex, new SFs could be observed still linked to neighbouring follicles within the cords (Fig. 3g). The cortico-medullary border was defined by newly formed follicles and a few remaining oogonia. Follicles with an early primary configuration appeared to 'bud-off' from the end of the ovigerous cords and be released into the medulla, either individually or in strings. SF at the true primary stage of development were also observed within the medulla (Fig. 3h).

At 11.2 months of gestation (Craig 1984), the fetal ovaries had a mean volume of $2.48 \mathrm{~cm}^{3}$. The OSE in fetus 4 was less densely packed and was now composed of only one to two layers of cuboidal cells. No naked oogonia were visible and all the oocytes were now contained within follicles of $\sim 47.5-75.0 \mu \mathrm{m}$ diameter. The cortex was typically $460 \mu \mathrm{m}$ deep and still contained some ovigerous cords surrounding follicles. Differentiation between the cortex and medulla was more obvious due to vascularisation and development of interstitial tissue in the medulla. In addition, follicles in the central medulla were becoming multilayered while those in the cortex remained as SF (Fig. 4a and b). Within the medulla, the first antral follicles (multilayered follicles with a developing antral cavity) had begun to form, demonstrating diameters of $1.0-1.6 \mathrm{~mm}$. The interstitial tissue showed a noticeable increase in vascularisation.

At 13.5 months, the mean weight of the two ovaries from which the sample blocks of tissue were obtained was $14.1 \mathrm{~g}$. Dense accumulations of interstitial cells were present in the medulla and these were interspersed with cords of elongated stromal cells. The stromal tissue of the cortex was now less dense than in the younger fetuses and SF were visible close to the OSE. Some growing follicles, both transitional (oocytes surrounded by more than one layer, but not two complete layers of granulosa cells) and secondary (oocytes surrounded by two complete layers of granulosa cells), were seen in the medulla and there was no obvious arrangement of smaller follicles being positioned more peripherally in the section. Growing antral follicles were now scattered throughout the medullary region of the ovary. The thecal layers of the follicles were well supplied with blood vessels, and it was difficult to differentiate theca externa cells from those of the surrounding interstitial cells.

\section{Germ cell counts}

A count of germ cell numbers gave values of 156 and 162 for the respective gonadal ridges in embryo 1 . The difficulty experienced in identifying germ cells in the remaining embryos made it impossible to calculate meaningful values for these embryonic stages. Germ cell numbers counted in the five fetuses are presented in Table 4. In general, germ cells whether naked oogonia or enclosed within follicles increased in number during the first half of gestation rising to 4464086 in the fetus at 11.2 months.

\section{Discussion}

\section{Developmental stage and ageing of the embryos}

Although each measurement and description of the gonads and ovaries were independent observations made in different individuals, the pattern of change over time is nonetheless suggestive of the pattern of development and, in the absence of longitudinal studies, provides the only data currently available.
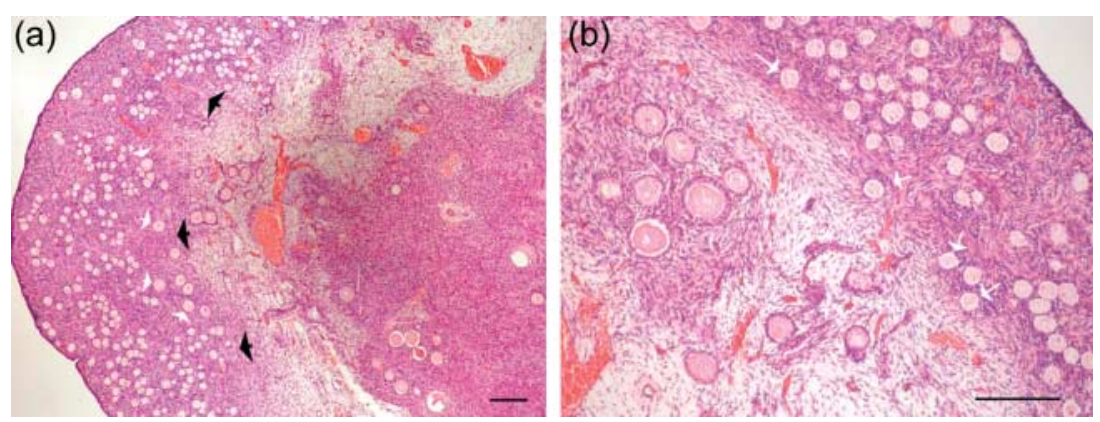

Figure 4 Sections through the ovaries of a mid-term (11.2 month) African elephant fetus. (a) The cortex and the medulla are now well-defined regions. Black arrowheads mark the inner limits of the former. Some small follicles in the inner cortex have initiated growth (white arrows). Scale bar $=100 \mu \mathrm{m}$. (b) Small follicles within the outer cortex are 'non-growing' while follicles within the medulla have started to grow. Some SF along the cortico-medullary border may be destined to progress further inwards when they will become committed to growth (white arrows). Blood vessels are seen within the cortex and medulla. Scale bar $=100 \mu \mathrm{m}$. 
Table 4 Numbers and distributions of oogonia and small and growing follicles in the ovaries of elephant fetuses.

\begin{tabular}{|c|c|c|c|c|c|c|c|c|}
\hline \multirow[b]{3}{*}{ Fetus no. } & \multirow{3}{*}{$\begin{array}{c}\text { Age } \\
\text { (months) }\end{array}$} & & & \multicolumn{5}{|c|}{ Follicles } \\
\hline & & \multicolumn{2}{|c|}{ Oogonia } & \multicolumn{2}{|c|}{ Small } & \multicolumn{2}{|c|}{ Growing } & \multirow[b]{2}{*}{ Total } \\
\hline & & Number & $\mathrm{c}: \mathrm{m}^{\mathrm{a}}$ & Number & $\mathrm{c}: \mathrm{m}$ & Number & $\mathrm{c}: \mathrm{m}$ & \\
\hline 1 & 4.8 & 1272139 & & 0 & & 0 & & 1272139 \\
\hline 2 & 5.3 & 1079080 & $63: 37$ & 55720 & $32: 68$ & 0 & & 1134800 \\
\hline 3 & 5.9 & 1322487 & 100:0 & 727390 & $81: 19$ & 0 & & 2049877 \\
\hline 4 & 11.2 & 0 & & 4003960 & 100:0 & 460126 & $0: 100$ & 4464086 \\
\hline
\end{tabular}

apercentage in cortex:percentage in medulla.

The ages of the five embryos used in the study were calculated initially from the ageing formula devised by Hildebrandt et al. (2007) based on the ultrasonically derived mass of the embryo (Table 1). However, the visual appearance of embryos 1,2 and 3 strongly suggested that they were more widely separated in age than the 2 days ascribed by the Hildebrandt et al. (2007) ageing formula. Accordingly, photographs of the embryos were compared with photographs included in the Hildebrandt et al.'s (2007) paper. As a starting point, embryo 2 appeared developmentally closer in age to the 81-day-old embryo (EF4) in the Hildebrandt et al.'s (2007) paper, so it was ascribed an age of 81 days, despite having a mass age of 77 days. Embryo 1 appeared less developed morphologically than embryo 2, so it was allotted its crown-rump length (CRL)- and mass- indicated age of 76 days. The mass of embryo 3 indicated an age of 78 days and its CRL an age of 87 days. A small amount of tissue was missing from the dorsal aspect of the embryo, suggesting that its true weight might have been higher than the figure recorded in Table 1. It also showed a less pronounced degree of flexure than its neighbouring embryos, which might have exaggerated its CRL age. As this embryo was clearly more advanced than embryo 2 and appreciably less advanced than embryo 4, it was allocated an age of 82 days. The weight and CRL predictions for embryo 4 were 80 and 89 days respectively and, as it was clearly more developmentally advanced than embryo 3, was allocated an age of 87 days. Similar calculations for embryo 5 gave ages of 94 and 98 days respectively (see Table 1), and it was therefore allocated an age of 96 days. However, this embryo weighed a full gram less than the embryo of 97 days (EF6) described in the Hildebrandt et al. (2007) paper.

\section{Morphology of the gonadal ridge and the developing ovary}

In mammals, the germ cells must be resident in the primordial gonad before sexual differentiation takes place. PGCs start entering the gonad during the 7th week of gestation in the human embryo (Langman 1981) and are thought to continue this invasion over a period of 14 days (Byskov \& Nielsen 2010). At this age, a human embryo is developmentally similar to the youngest elephant embryo (76 days old) described in this study. In this elephant (embryo 1), PGCs were observed external to the indifferent gonad while germ cells were present within the gonad. The total number of PGCs that migrate from the extra-embryonic yolk sac in the elephant is not known, but in this embryo, 162 and 156 germ cells were counted within the respective gonadal ridges. In embryos 3 and 4, germ cells similar to those observed in embryo 1 were still visible within the gonad and, although not actually counted, they did not appear to have increased greatly in numbers when compared with embryo 1 . This phenomenon may have been due to the germ cells undergoing mitotic division with a concomitant decrease in size due to higher mitotic activity (Oktem \& Urman 2010) making them difficult to recognise in the gonad. No additional germ cells were seen in tissues external to the gonad in embryos 3 and 4, which suggests that embryo 1 may have been nearing the end of the migratory phase of the PGCs. Or alternatively, the age difference between embryos 1 and 4 was greater than the 4 days suggested by the ageing formula of Hildebrandt et al. (2007) or the 11 days allocated in this study. Embryo 5 at 96 days of age was calculated to be 18 days older than embryo 1 and may therefore have entered the period of sex differentiation, previously suggested to occur around the age of 105 days at an embryonic weight of $9 \mathrm{~g}$ in the elephant (Glickman et al. 2005). This could not be confirmed by light microscopic examination of the gonad as it was a homogenous cluster of both germinative and somatic cells. A specific staining method for PGCs and oogonia would be required to be able to determine the precise developmental stage of the gonad and to count the germ cells at this age.

Fetus 1 at 4.8 months of age exhibited relatively large ovaries attached to a comparatively small and underdeveloped uterus. In terms of follicle formation, it approximated to a 55-day-old sheep fetus as described in detail by Sawyer et al. (2002). Oogonia in various stages of mitosis were present throughout the ovary within 'germline cysts' described as groups of germ cells thought to be formed by successive incomplete divisions of a single cell (Gondos \& Zamboni 1969). Such 'cyst' formation is suggested to be well conserved between 
both vertebrates and invertebrates during evolution (Pepling et al. 1999, Pepling 2012). In the present elephant fetus, these cysts or nests were surrounded by tracts of fibroblasts associated with which were a few smaller round cells of unknown origin that were destined to become the pre-granulosa cells and later the granulosa cells surrounding oocytes to form early follicles. Pre-granulosa cells are distinguishable histologically from other mesenchymal cells by their direct physical contact with at least one oogonium (Juengel et al. 2002). The embryonic origin of these cells is unclear, likely candidate precursor cells being those of the rete ovarii (Byskov \& Lintern-Moore 1973, Zamboni et al. 1979) or the surface epithelium (Sawyer et al. 2002). It is also possible that granulosa cells may derive in separate waves from both these populations (Eppig \& Handel 2012, Mork et al. 2012). The first wave supplying the pre-granulosa cells for follicles developing within the medulla while the second wave is associated with follicles developing in the cortex. Granulosa cell origins may also vary between species (Juengel et al. 2002, Mork et al. 2012). No SF development was observed in fetus 1.

The ovaries of fetus 2 (5.3 months of gestation) paralleled closely the developmental stage of a 75-dayold sheep fetus (Sawyer et al. 2002). A small number of SF were present within the cortico-medullary region while the remainder of the cortex was packed with oogonia within the newly formed ovigerous cords. Although these cords seemed to form in the same manner as described in sheep (Sawyer et al. 2002), the basal lamina was very difficult to discern in haematoxylin and eosin (H\&E) sections. The SF follicles were early primary in nature with constituent granulosa cells that were either flat or cuboidal. True primordial follicles are rarely seen in the elephant ovary, although 'cometlike' follicles with a prolate shape, as described in sheep by Sawyer et al. (2002), are observed frequently. Some SF and oogonia in nests were also visible throughout the medulla but in much lower numbers than in the presumptive cortex. These germ cells were comparable to the 'medullary germ cells' described in the fetal sheep ovary by Sawyer et al. (2002) but with the noticeable difference that they associated with somatic pregranulosa cells to create follicles.

In all species studied to date, follicle formation begins in the innermost part of the ovary and spreads gradually outwards towards the periphery (Byskov \& Nielsen 2010). In the elephant, follicle formation occurs concomitantly at the presumptive cortico-medullary border and within the central region of the ovary. Follicles positioned at the border emerge from ovigerous cords as described by Sawyer et al. (2002) while the centrally placed follicles arise more independently from the oogonial nests. The suggestion by Pepling (2006) that meiotic onset is either stimulated by a medullary factor, or is restricted by a cortical factor, may explain the spasmodic initiation of folliculogenesis throughout the presumptive medulla. The boundary between the cortex and the medulla is not static during adult life and may be described as the mid-point between the follicles of the cortex and the blood vessels of the medulla (Fawcett 1997). However, this definition is not consistent with events in the elephant fetal ovary as the cortex is well vascularised and follicles occur within the medulla. Nevertheless, a definite cortico-medullary border does become apparent in the elephant fetal ovary from $\sim 5$ months of gestation (Figs $3 \mathrm{e}, 4 \mathrm{a}$ and $\mathrm{b}$ ).

At 5.9 months of gestation (Fetus 3), SF formation was advanced and the pycnotic nuclei of presumptive atretic oogonia and oocytes were observed as 'black spots' in the sections, thereby highlighting the ongoing balance between atresia and mitosis within the pool of germ cells in the fetal ovary. The ratio between oogonia and SF within the cortex of fetus 3 was close to 2:1 (Table 4). These observations equate well with those in the fetal ovary of the sheep at 90 days of gestation (Sawyer et al. 2002).

By mid-pregnancy (11.2 months; fetus 4 ), the follicle pool was contained within the more clearly defined cortical region of the ovary while the follicles within the medulla had started to enlarge to give rise to the first antral follicles observed. The follicle reserve within the cortex is thought to be held in a 'dormant state' by the action of local factors (Adhikari \& Liu 2009). Such inhibitory molecules for follicle activation may be absent from the medulla of the elephant fetal ovary so that follicles can enter primary recruitment and start to grow there. Segments of the ovigerous cords were still apparent in the medulla in association with streams of stromal cells and the dark staining interstitial tissue that comes to play such a prominent role in the elephant fetal gonad throughout the second half of pregnancy was now visible (Stansfield \& Allen 2012, Stansfield et al. 2012). In this 11.2-month fetus, the follicle, oocyte and nuclear diameters were bigger than those observed before (5.9 months) or after (15.2 months; Table 2) this stage during gestation (Stansfield et al. 2012), and they exceeded the diameters measured in mature animals (Stansfield et al. 2011b). Byskov \& Nielsen (2010) pointed out that all first-generation oocytes in the mammalian ovary begin to grow immediately on reaching the diplotene stage of meiosis I and are therefore committed to further growth and wastage. Thus, it is interesting to speculate that the follicles present and measured in the present 11.2-month fetus are these very first follicles (their oocyte and nuclear diameter suggest that they are growing), which give rise to the antral follicles formed during the second half of pregnancy. By 13.5 months of gestation, the considerable enlargement that typifies the elephant fetal ovary during the second half of gestation had commenced as a result of the now clear increase in volume of interstitial tissue. 
While the source of the pre-granulosa cells could not be determined accurately in the present samples, the pattern of staining for activity of $3 \beta-\mathrm{HSD}$ in the fetal ovaries would seem to support a mesonephric origin, as described by Zamboni et al. (1979), rather than an epithelial origin, as described by Sawyer (2002). Quirke et al. (2001) observed that mesonephric and mesothelial cells of the presumptive medulla in the fetal sheep ovary stain positively for $3 \beta-\mathrm{HSD}$ while those of the presumptive cortex do not. The granulosa cells in the mid-gestation elephant fetal ovary stain positively and precisely for $3 \beta-$ HSD (Stansfield et al. 2012), as do the Sertoli cells in the elephant fetal testis at the same stage (Allen et al. 2005). However, a contribution from the surface epithelium cannot be ruled out. The further theory by Byskov \& Nielsen (2010) that the oocyte may be capable of stimulating neighbouring somatic cells to differentiate into granulosa cells is an attractive alternative.

\section{Germ cell counts}

Only 318 PGCs were counted in the undifferentiated gonad of embryo 1. This is many fewer than the 11000 germ cells calculated to reside in the undifferentiated mouse fetal gonad (Tam \& Snow 1981), although it is similar to the 450-1400 germ cells counted in the human embryo by Witschi (1948). The counts in the elephant fetal gonads may have been reduced by the initiation of mitosis producing smaller sized oogonia that could not be positively identified as such. Similar counts were not attempted in the other three embryos due to the difficulty in accurately distinguishing mitotic germ cells from their surrounding pre-granulosa cells (Fig. $2 \mathrm{~d}$ and f). Further counts using pluripotent cell markers like Oct4 and VASA (Kerr et al. 2008) to identify oogonia are planned when new samples become available.

The distribution of follicles within the fetal ovaries is listed in Table 4. It was interesting to find that the number of oogonia remained at around 1-1.3 million between 4.8 and 5.9 months of gestation when they were dividing mitotically and also entering into meiosis to form SFs. Thus, in the elephant, entry into meiosis, as determined by the development of the first follicles, was first observed around 5 months of gestation and persists through to 11 months. Although oogonia were not visible at 11.2 months in fetus 4 , examination of the ovaries of another 11.3-month-old fetus from a previous study (Allen et al. 2005) revealed a small number of oogonia within and directly below the OSE. From this observation, it may be deduced that fetus 4 marked the end of the 6-month period of mitotic-meiotic transition. Such a conclusion would concur with the observation by Deanesly (1977) that the period of entry into meiosis is extended in animals with longer gestation periods. This interval is 22 days longer in the elephant than in women, although, given the considerable duration of gestation in the elephant, it might have been expected to be longer.

As in other species, the peak number of germ cells counted in the elephant fetal ovary (4.5 million) occurred towards the end of the period of mitoticmeiotic transition. The 450000 growing follicles counted in the medulla of the 11-month fetus 4 were destined to grow to the mid-antral size $(5 \mathrm{~mm})$ before becoming atretic. Such atresia reflects a considerable loss of genetic material, although, as shown in Table 5, this figure in the elephant fetus is still well below the numbers of follicles recorded to be lost during fetal life in other species. Antral follicles have been observed to develop in the fetal ovaries of other species, most notably the giraffe (Kellas 1958, Benirschke 2007), but the stimulus for such growth and any possible biological significance of it remain unknown.

In conclusion, some developmental milestones in the ovary of the elephant embryo and fetus have been described for the first time. Progression of PGCs in the indifferent gonad terminates around 76 days of gestation, entry into meiosis and first follicle formation commences around 5 months when many granulosa cells have already assumed a cuboidal shape and peak numbers of follicles are present at mid-gestation towards the end of the 6-month mitotic-meiotic transition period. It appears that the cortex of the elephant fetal ovary at midgestation has already reached a developmental status of the ovaries of many other mammals at full term. Furthermore, ovarian development during the second half of gestation is directed more towards the medulla and its clearly significant role in steroid hormone synthesis.

Table 5 Number of small follicles (SF) in the reserves of different mammalian species.

\begin{tabular}{llllllll}
\hline $\begin{array}{l}\text { Age or stage } \\
\text { of gestation }\end{array}$ & Mouse $^{\mathrm{a}}$ & Rat $^{\mathrm{b}}$ & $\begin{array}{l}\text { Domestic } \\
\text { dog }^{\mathrm{c}}\end{array}$ & Sheep $^{\mathrm{d}}$ & Cow $^{\mathrm{c}}$ & Human $^{\mathrm{e}}$ & \multicolumn{1}{c}{ Elephant $^{\mathrm{f}}$} \\
\hline Peak number & $250000^{\mathrm{f}}$ & $50-75 \times 10^{3 \mathrm{~g}}$ & NA & $9 \times 10^{6}(75 \mathrm{~d})$ & $2.7 \times 10^{6}(110 \mathrm{~d})$ & $7 \times 10^{6}(5 \mathrm{~m})$ & $4.5 \times 10^{6}(11 \mathrm{~m})$ \\
Early gestation & NA & NA & NA & NA & $16 \times 10^{3}(50 \mathrm{~d})$ & $26-250 \times 10^{3}(42 \mathrm{~d})^{\mathrm{h}}$ & $1.2 \times 10^{6}(4.8 \mathrm{~m})$ \\
Mid-gestation & NA & NA & NA & $170-200 \times 10^{3}(90 \mathrm{~d})$ & $107 \times 10^{3}(170 \mathrm{~d})$ & $9.0 \times 10^{6 \mathrm{i}}(110 \mathrm{~d})$ & $4.5 \times 10^{6}(11 \mathrm{~m})$ \\
Late gestation & NA & NA & NA & $82 \times 10^{3}(135 \mathrm{~d})$ & $68 \times 10^{3}(240 \mathrm{~d})$ & NA & $850 \times 10^{3 \mathrm{j}}$ \\
Birth & 7924 & $10-15 \times 10^{3 \mathrm{~g}}$ & $700 \times 10^{3}$ & $82 \times 10^{3 \mathrm{~g}}$ & $135 \times 10^{3 \mathrm{~g}}$ & $1.5 \times 10^{6}$ & $560 \times 10^{3 \mathrm{j}}$ \\
\hline
\end{tabular}

Information in brackets indicates age in days $(\mathrm{d})$ or months $(\mathrm{m})$ post-conception.

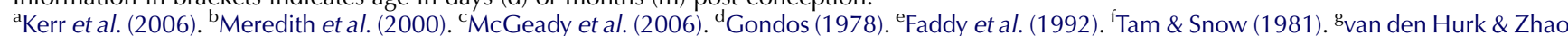
(2005). ' Bendsen et al. (2006). 'Mamsen et al. (2011). 'Stansfield et al. (2012). 


\section{Materials and Methods}

Four young embryos of indeterminate gender harvested during the first 100 days of gestation and four pairs of ovaries from female fetuses recovered between 4.8 and 11.2 months of gestation were collected from pregnant elephants culled in family groups for management reasons in the Savé Valley Conservancy in Zimbabwe. An additional embryo aged 96 days was kindly donated by $\operatorname{Dr} \mathrm{R} M$ Laws from his collections in the 1960's (Laws 1969) and two paraffinembedded samples of fetal ovaries aged 11.3 and 13.5 months were available from a previous study (Allen et al. 2005). CRL was measured from the vertex of the skull to the base of the tail (Arey 1966) and this figure, together with body weight (g), was used to age each embryo/fetus using the formulae described by Craig (1984) and Hildebrandt et al. (2007).

Within $2 \mathrm{~h}$ of death, the whole embryo or the dissected ovaries of the fetuses was immersed in $4 \% \mathrm{v}: \mathrm{v}$ neutral buffered formalin; weights and CRLs were measured following fixation. The embryos were embedded whole in paraffin wax in large histology cassettes and serially sectioned along the sagittal plane at $5 \mu \mathrm{m}$ thickness due to the small size of the gonadal ridge, which was an unknown factor before sectioning took place. Every 5th section was mounted on a slide and stained with H\&E. The four sets of fetal ovaries were bisected before being placed in cassettes from which ten uniformly spaced $25 \mu \mathrm{m}$-thick transverse sections were cut, placed on slides and stained with H\&E. The slides were examined for morphological development and the germ cell numbers were counted using stereological protocols (Howard \& Reed 2005). Briefly, for embryos 1-5, every 5th serial section was stained and an unbiased counting frame was tessellated over the whole area of the tissue on each slide in order to count the number of germ cells; these were identified by a nucleus of 10.0-12.5 $\mu \mathrm{m}$ diameter, which contrasted clearly with nuclear diameters of about $5 \mu \mathrm{m}$ for the smaller cells in the region. The formula of Abercrombie (1946) was used to calculate the number of germ cells as described previously by Mounton (2002). For the four sets of fetal ovaries, stereological calculations were carried out using the unbiased brick to determine density and Cavalieri's estimator to determine volume. These methods have been described in detail and validated previously by Stansfield et al. (2011a).

\section{Declaration of interest}

The authors declare that there is no conflict of interest that could be perceived as prejudicing the impartiality of the research reported.

\section{Funding}

This project was kindly funded, in part, by the China Wildlife Conservation Association and The National Research Foundation of South Africa.

\section{Acknowledgements}

The authors sincerely thank the owners, managers and staff of the Savé Valley Conservancy, Zimbabwe, for their continued help and patience in collecting the required samples and for their generous hospitality and backing for The Elephant Research and Conservation Unit. Thanks are also offered to Mrs Sue Gower for her preparation of the $25 \mu \mathrm{m}$ sections.

\section{References}

Abercrombie M 1946 Estimation of nuclear population from microtome sections. Anatomical Record 94 236-247. (doi:10.1002/ar.1090940210)

Adhikari D \& Liu K 2009 Molecular mechanisms underlying the activation of mammalian primordial follicles. Endocrine Reviews 30 438-464. (doi:10.1210/er.2008-0048)

Aitken RJ, Findlay JK, Hutt KJ \& Kerr JB 2011 Apoptosis in the germ line. Reproduction 141 139-150. (doi:10.1530/REP-10-0232)

Allen WR, Mathias S \& Ford M 2005 Placentation in the African elephant, Loxodonta africana. IV. Growth and function of the fetal gonads. Reproduction 130 713-720. (doi:10.1530/rep.1.00696)

Anderson R, Copeland TK, Scholer H, Heasman J \& Wylie C 2000 The onset of germ cell migration in the mouse embryo. Mechanisms of Development 91 61-68. (doi:10.1016/S0925-4773(99)00271-3)

Arey LB 1966 Developmental Anatomy. A Textbook and Laboratory Manual of Embryology. 7th Edn. Philadelphia, PA, USA: W B Saunders Company.

Bendsen E, Byskov AG, Andersen C \& Westergaard LG 2006 Number of germ cells and somatic cells in human fetal ovaries during the first weeks after sex differentiation. Human Reproduction 21 30-35. (doi:10.1093/ humrep/dei280)

Benirschke K 2007 Comparative placentation: giraffe (Giraffa camelopardalis). In Comparative Placentation: http://placentation.ucsd.edu/ homefs.html.

Bowles J \& Koopman P 2007 Retinoic acid, meiosis and germ cell fate in mammals. Development 134 3401-3411. (doi:10.1242/dev.001107)

Byskov AG \& Lintern-Moore S 1973 Follicle formation in the immature mouse ovary; the role of the rete ovarii. Journal of Anatomy 116 207-217.

Byskov AG \& Nielsen M 2010 Ontogeny of the mammalian ovary. In Biology and Pathology of the Oocyte. 1st Edn, pp 13-28. Eds AO Trounson \& RG Gosden. Cambridge, UK: Cambridge University Press.

Childs AJ, Cowan G, Kinnell HL, Anderson RA \& Saunders PK 2011 Retinoic acid signalling and the control of meiotic entry in the human fetal gonad. PLoS ONE 6 e20249. (doi:10.1371/journal.pone.0020249)

Craig GC 1984 Foetal mass and date of conception in African elephants: a revised formula. South African Journal of Science 80 512-516.

Deanesly R 1977 Germ cell proliferations in the fetal horse ovary. Cell and Tissue Research 185 361-371. (doi:10.1007/BF00220296)

Eppig JJ \& Handel MA 2012 Origins of granulosa cells clarified and complexified by waves. Biology of Reproduction 86 1-2. (doi:10.1095/ biolreprod.111.096651)

Faddy MJ, Gosden RG, Gougeon A, Richardson SJ \& Nelson JF 1992 Accelerated disappearance of ovarian follicles in mid-life: implications for forecasting menopause. Human Reproduction 7 1342-1346.

Fawcett DW 1997 Female reproductive system. In Bloom \& Fawcett: Concise Histology. 1st Edn, pp 269-284. Ed RP Jensh. New York, NY, USA: Chapman and Hall.

de Felici M 2010 Germ stem cells in the mammalian adult ovary: considerations by a fan of the primordial germ cells. Molecular Human Reproduction 16 632-636. (doi:10.1093/molehr/gaq006)

Gaeth AP, Short RV \& Renfree MB 1999 The developing renal, reproductive, and respiratory systems of the African elephant suggest an aquatic ancestry. PNAS 96 5555-5558. (doi:10.1073/pnas.96.10. 5555)

Glickman SE, Short RV \& Renfree MB 2005 Sexual differentiation in three unconventional mammals: spotted hyenas, elephants and tammar wallabies. Hormones and Behaviour 48 403-417. (doi:10.1016/j.yhbeh. 2005.07.013) 
Gondos B \& Zamboni L 1969 Ovarian development: the functional importance of germ cell interconnections. Fertility and Sterility $\mathbf{2 0}$ $176-177$.

Gondos B 1978 Oogonia and oocytes in mammals. In The Vertebrate Ovary; comparative biology and evolution. 1st Edn, pp 853. Ed, RE Jones. New York, NY, USA: Plenum Press.

Gosden RG 2004 Germline stem cells in the postnatal ovary: is the ovary more like a testis? Human Reproduction Update 10 193-195. (doi:10.1093/humupd/dmh023)

Gougeon A \& Notarianni E 2011 There is no neo-oogenesis in the adult mammalian ovary. Journal of Turkish-German Gynecological Association 12 270-273. (doi:10.5152/jtgga.2011.63)

Hildebrandt T, Drews B, Gaeth AP, Goeritz F, Hermes R, Schmitt D, Gray C, Rich P, Streich WJ, Short RV et al. 2007 Foetal age determination and development in elephants. Proceedings of the Royal Society B, Biological Sciences 274 323-331. (doi:10.1098/rspb.2006.3738)

Howard CV \& Reed MG 2005 Unbiased Stereology. Oxford: BIOS Scientific Publishers. 2nd Edn, pp 271. Ed Jones C. Oxford, UK: BIOS Publishers.

van den Hurk R \& Zhao J 2005 Formation of mammalian oocytes and their growth, differentiation and maturation within ovarian follicles. Theriogenology 63 1717-1751.

Juengel JL, Sawyer HR, Smith PR, Quirke LD, Heath DA, Lun S, Wakefield SJ \& McNatty KP 2002 Origins of follicular cells and ontogeny of steroidogenesis in ovine fetal ovaries. Molecular and Cellular Endocrinology 191 1-10. (doi:10.1016/S0303-7207(02)00045-X)

Kellas LM 1958 Ovaries of some fetal and prepubertal giraffes. Nature 181 487-488. (doi:10.1038/181487a0)

Kerr JB, Duckett R, Myers M, Britt KL, Mladenovska T \& Findlay JK 2006 Quantification of healthy follicles in the neonatal and adult mouse ovary: evidence for maintenance of primordial follicle supply. Reproduction 132 95-109.

Kerr CL, Hill CM, Blumenthal PD \& Gerhart JD 2008 Expression of pluripotent stem cell markers in the human fetal ovary. Human Reproduction 23 589-599. (doi:10.1093/humrep/dem411)

Langman J 1981 Medical Embryology. 4th Edn, pp 383. Baltimore/London: Williams and Wilkins.

Laws RM 1969 Aspects of reproduction in the African elephant, Loxodonta africana. Journal of Reproduction and Fertility Supplement 6 193-217.

Mamsen LS, Lutterodt MC, Andersen EW, Byskov AG \& Andersen CY 2011 Germ cell numbers in human embryonic and fetal gonads during the first two trimesters of pregnancy: analysis of six published studies. Human Reproduction 26 2140-2145.

McGeady TA, Quinn PJ, FitzPatrick ES \& Ryan MT 2006 Male and female reproductive systems. In Veterinary Embryology. 1st Edn, pp 245-251. Oxford, UK: Blackwell Publishing.

McLaren A 2003 Primordial germ cells in the mouse. Developmental Biology 262 1-15. (doi:10.1016/S0012-1606(03)00214-8)

Meredith S, Dudenhoeffer G \& Jackson K 2000 Classification of small type $\mathrm{B} / \mathrm{C}$ follicles as primordial follicles in mature rats. Journal of Reproduction and Fertility 119 43-48.

Meyer JM, Walker SL, Freeman EW, Steinetz BG \& Brown JL 2004 Species and fetal gender effects on the endocrinology of pregnancy in elephants. General and Comparative Endocrinology 138 263-270. (doi:10.1016/ j.ygcen.2004.06.010)

Mork L, Maatouk DM, McMahon JA, Guo JJ, Zhang P, McMahon AP \& Capel B 2012 Temporal differences in granulosa cell specification in the ovary reflect distinct follicle fates in mice. Biology of Reproduction $\mathbf{8 6}$ 1-9. (doi:10.1095/biolreprod.111.095208)

Moss C \& Poole JH 1983 Relationships and social structure of African elephants. In Primate Social Relationships: an Integrated Approach. pp 314-325. Ed RE Hinde. Oxford, UK: Blackwell Scientific.
Mounton PR 2002 Principles and practices of unbiased stereology. 1st Edn, pp 214. Baltimore, MD, USA: John Hopkins University Press.

Oktay K 1995 Proliferating cell nuclear antigen marks the initiation of follicular growth in the rat. Biology of Reproduction 53 295-301. (doi:10.1095/biolreprod53.2.295)

Oktem O \& Urman B 2010 Understanding follicle growth in vivo. Human Reproduction 25 2944-2954. (doi:10.1093/humrep/deq275)

Pepling ME 2006 From primordial germ cell to primordial follicle: mammalian female germ cell development. Genesis 44 622-632. (doi:10.1002/dvg.20258)

Pepling ME 2012 Follicular assembly: mechanisms of action. Reproduction 143 139-149. (doi:10.1530/REP-11-0299)

Pepling ME, de Cuevas M \& Spradling AC 1999 Germline cysts: a conserved phase of germ cell development? Trends in Cellular Biology 9 257-262. (doi:10.1016/S0962-8924(99)01594-9)

Quirke LD, Juengel JL, Tisdall DJ, Lun S, Heath DA \& McNatty KP 2001 Ontogeny of steroidogenesis in the fetal sheep gonad. Biology of Reproduction 65 216-228. (doi:10.1095/biolreprod65.1.216)

Reynaud K \& Driancourt MA 2000 Oocyte attrition. Molecular and Cellular Endocrinology 163 101-108. (doi:10.1016/S0303-7207(99) 00246-4)

Sawyer HR, Smith P, Heath DA, Juengel JL, Wakefield SJ \& McNatty KP 2002 Formation of ovarian follicles during fetal development in sheep. Biology of Reproduction 66 1134-1150. (doi:10.1095/biol reprod66.4.1134)

Stansfield FJ \& Allen WR 2012 Luteal maintenance of pregnancy in the African elephant (Loxodonta africana). Reproduction 143 845-854. (doi:10.1530/REP-12-0032)

Stansfield FJ, Nöthling JO \& Ansari T 2011a The distribution of small preantral follicles within the ovaries of prepubertal African elephants (Loxodonta africana). Animal Reproduction Science 129 96-103. (doi:10.1016/j.anireprosci.2011.10.009)

Stansfield FJ, Picton HM \& Nöthling JO $2011 b$ Early primary-rather than primordial follicles constitute the main follicular reserve in the African elephant (Loxodonta africana). Animal Reproduction Science 123 112-118. (doi:10.1016/j.anireprosci.2010.11.003)

Stansfield FJ, Nöthling JO \& Allen WR 2012 Growth and development of the ovary and small follicle pool from mid fetal life to pre-puberty in the African elephant (Loxodonta africana). BMC Veterinary Research 8119 (doi:10.1186/1746-6148-8-119)

Tam PP \& Snow MH 1981 Proliferation and migration of primordial germ cells during compensatory growth in mouse embryos. Journal of Embryology and Experimental Morphology 64 133-147.

Van Wezel IL \& Rodgers RJ 1996 Morphological characterization of bovine primordial follicles and their environment in vivo. Biology of Reproduction 55 1003-1011. (doi:10.1095/biolreprod55.5.1003)

Witschi E 1948 Migration of the germ cells of human embryos from the yolk sac to the primitive gonadal folds. Contributions to Embryology 32 67-80.

Zamboni L, Bezard J \& Mauleon P 1979 The role of the mesonephros in the development of the sheep fetal ovary. Annals of Biology, Biochemistry and Biophysics 19 1153-1178. (doi:10.1051/rnd:19790801)

Received 2 August 2012

First decision 10 September 2012

Accepted 18 September 2012 